\title{
O “ACORDA, CIVIL!" COMO FERRAMENTA PARA A PARTICIPAÇÃO DISCENTE NO PROCESSO DE APRIMORAMENTO DA QUALIDADE DO CURSO DE ENGENHARIA CIVIL DA UNIVERSIDADE FEDERAL DE ALAGOAS
}

Ariana C. S. de Magalhães'; Bruno L. R. Saldanha2; Christian C; de Oliveira³; Jáder V. A. Pereira ${ }^{4}$; Luan Y. L. Silva ${ }^{5}$; Luis H. N. Cavalcante ${ }^{6}$; Mateus F. M. de Oliveira ${ }^{7}$; Karoline A. de M. Moraes ${ }^{8}$

\section{1, 2, 3, 4, 5, 6, 7, 8 Universidade Federal de Alagoas Email do Autor: ariana.mmagalhaes@gmail.com}

PET Engenharia Civil, Universidade Federal de Alagoas, Maceió, Alagoas

Palavras - chave: Ensino em Engenharia; Melhoria de curso; Protagonismo discente.

\begin{abstract}
Introdução
O curso de Engenharia Civil na Universidade de Alagoas (UFAL) foi fundado no ano de 1955, sendo dotado de grande trajetória histórica, chegando a obter conceito máximo no Exame Nacional de Desempenho de Estudantes (Enade) no ano de 2009. Em uma perspectiva atual, o curso necessita de uma atualização para que seja possível oferecer suporte para o desenvolvimento de algumas das habilidades esperadas em um profissional da área.
\end{abstract}

Como forma de identificar e diagnosticar as melhorias necessárias para 0 curso, o PET Engenharia Civil da Universidade Federal de Alagoas idealizou o "Acorda, Civil!". A atividade visou englobar a majoritária opinião dos alunos de 
Engenharia Civil da UFAL, que através dos variados grupos de discussão, conseguiram expor suas ideias e preocupações sobre as decorrentes deficiências presentes no curso, de forma que os agentes atuantes da atividade seriam não apenas os petianos, mas também o próprio corpo discente do curso, colaborando para a criação do senso de urgência de mudança do curso.

\section{Objetivos}

O seguinte trabalho busca explanar de forma breve todas as etapas de construção e execução da atividade "Acorda, Civil!", destacando o trabalho de mobilização de diferentes grupos discentes bem como a proposta de intervenção da atividade na estruturação do curso de Engenharia Civil no tocante às demandas discentes e melhorias no perfil de formação, habilidades e competências frente ao atual panorama.

\section{Metodologia}

Inicialmente, houve uma apresentação da atividade no Colegiado do curso, uma vez que é a instância responsável pelo acompanhamento do curso, visando assim obter o apoio dos docentes para o que se estava propondo.

A atividade, no seu estágio inicial, ficou concentrada em reuniões semanais entre os membros do PET. Nas reuniões foram utilizados como subsídio para nortear o "Acorda, Civil!" alguns modelos como a Liderança de Transformação (KOTTER, 2017) e modelos de eventos internos ao PET como a estrutura de execução do próprio Encontro Nacional dos Grupos PET (ENAPET). Após um mês de reuniões internas os outros grupos acadêmicos do Centro de Tecnologia - CTEC da UFAL foram inseridos à concepção por meio de reuniões entre representantes desses grupos e membros do PET Engenharia Civil. Dos grupos acadêmicos com ênfase no curso de Engenharia Civil participaram: Centro Acadêmico de Engenharia Civil, Empresa Júnior de Engenharia Civil - EJEC, Programa de Capacitação Discente - PEC e PET Ciência e Tecnologia, além do PET Engenharia Civil. A cada reunião semanal da atividade, os grupos levavam as deliberações para discussão interna e na reunião subsequente as opiniões eram mais uma vez discutidas e 
compartilhadas entre os grupos. Desse modo, foi possível definir a seguinte estruturação para o "Acorda, Civil!":

1 - Grupos de discussão (GD);

2 - Encaminhamentos com sugestões do corpo discente;

3 - Assembleia;

Nos grupos de discussão foram estabelecidos temas apontados pela comissão organizadora da atividade, de acordo com demandas discentes previamente analisadas e comumente vistas através de questionários de avaliação docente e encaminhamentos direcionados ao Centro Acadêmico. Os temas das discussões foram os seguintes:

1. Pré-requisitos;

2. Metodologias de ensino e avaliação;

3. Estágio;

4. Falta de prática;

5. Ciclo básico e distribuição de professores de outras unidades acadêmicas;

6. Carga horária efetiva e aparente.

Cada grupo de discussão era autônomo, havendo um presidente - condutor da discussão, e um secretário - responsável pelo registro da discussão e dos encaminhamentos elaborados a partir das demandas do grupo. Por sua vez, na assembleia foram apresentados todos os encaminhamentos, os quais, após apreciação, eram votados como demandas gerais da plenária ou não. A assembleia estava aberta a toda comunidade discente e docente do curso de Engenharia Civil. Alguns docentes participaram também dos grupos de discussão.

\section{Resultados e Discussão}

A partir da inicial concepção do planejamento da atividade, a apresentação do "Acorda, Civil!" foi uma etapa imprescindível para o seu cumprimento de maneira integrada e colaborativa, já que, a partir deste momento, foram efetivados o apoio do Colegiado e a compreensão da importância da 
participação discente no processo de contínuo aprimoramento da qualidade de ensino e aprendizagem (CUGNASCA, 2001).

Desta maneira, foi dada a partida de construção da atividade em um diálogo entre docentes e discentes, através do qual o estudante deixa de ser um elemento meramente passivo no processo de ensino-aprendizagem e passa a ser um elemento ativo, contribuindo para a manutenção da qualidade almejada nesse processo (CUGNASCA, 2001). Tal parceria com os docentes contribuiu para que estes incorporassem o objetivo da atividade e passassem a contribuir ativamente com o seu desenvolvimento, tanto no incentivo ao engajamento discente, quanto na sua efetiva participação durante os Grupos de Discussão e assembleia, contribuindo sem tomar o espaço de exposição de ideias e opiniões que, por idealização da atividade, tinha caráter estudantil.

\section{Resultados para o curso e graduação}

De acordo com o Manual de Orientações Básicas (MOB) do Programa de Educação Tutorial (SESU, 2006), a inserção do grupo PET dentro do curso permite que tanto a capacidade de trabalho em equipe, quanto a percepção da responsabilidade coletiva e do compromisso social se disseminem para toda a comunidade acadêmica na qual está inserido. Dessa forma, nota-se que o "Acorda, Civil!" atende a esse objetivo do Programa, dentre outros, como a disseminação de ideias e práticas entre o conjunto dos alunos do curso.

Um dos produtos conquistados em prol da melhoria do curso consiste na efetividade do acompanhamento e divulgação, por parte do Centro Acadêmico de Engenharia Civil (CAEC), do andamento das demandas encaminhadas pelos discentes e enviadas ao colegiado, com uma periodicidade de 3 meses.

A partir desta mobilização e da apresentação das demandas compiladas para o Conselho da Unidade Acadêmica e para o Colegiado, a filosofia da atividade hoje começa a ser incorporada por outros cursos de graduação. Além disso, o "Acorda, Civil!" passou de uma atividade que era pertencente apenas ao planejamento do Programa de Educação Tutorial de Engenharia Civil da 
Universidade Federal de Alagoas, para se tornar uma atividade inerente dos grupos discentes do curso de Engenharia Civil.

\section{Resultados para os petianos}

Do processo de planejamento da atividade, articulação com o colegiado, convocação dos grupos discentes, formulação de textos guias, divulgação e presidência das mesas de discussão, vê-se que todo o processo da atividade proporcionou uma gama diversa de trabalho de competências para os petianos envolvidos, tais como: liderança, comunicação escrita e oral, resolução de problemas, entre outros.

\section{Conclusão}

A partir do exposto é possível visualizar no "Acorda, Civil!" uma grande ferramenta de disseminação da educação tutorial e do compartilhamento da responsabilidade pela realidade social na qual o curso está inserido, em toda a classe discente e docente. A atividade propõe desta maneira que estudantes e professores sejam atores ativos da dinâmica de transformação do processo de ensino-aprendizagem e da própria lógica de aprimoramento da qualidade do curso.

\section{Referências}

KOTTER, John. The 8-step Process for Leading Change, 2017. Disponível em <https://www.kotterinternational.com/8-steps-process-for-leading-change/>. Acesso em 05 dez. 2017.

P. S. CUGNASCA. A Participação Discente no Processo de Manutenção da Qualidade de Ensino de Engenharia. In: Anais do XXIX COBENGE Congresso Brasileiro de Ensino de Engenharia, Porto Alegre - RS, 2001.

SECRETARIA DE EDUCAÇÃO SUPERIOR. Manual de Orientações Básicas - PET. Brasília: SESu, 2006. 